\title{
ANALISIS KESESUAIAN LAHAN UNTUK PENGEMBANGAN EKOWISATA MANGROVE KURI CADDI KABUPATEN MAROS SULAWESI SELATAN
}

\section{ANALYSIS OF LAND SUITABILITY FOR THE DEVELOPMENT OF KURI CADDI MANGROVE ECOTOURISM, MAROS REGENCY, SOUTH SULAWESI}

\author{
Rusmin Nuryadin ${ }^{1)}$, Muhammad Arhan Rajab ${ }^{2)}$ \\ ${ }^{1,2}$ Program Studi Manajemen Pariwisata, Sekolah Tinggi Pariwisata Tamalatea Makassar \\ ${ }^{1}$ Email : rusminnuryadin@stipartamalatea.ac.id
}

\begin{abstract}
ABSTRAK
Dalam pengembangan kawasan ekowisata mangrove memerlukan sebuah kajian terkait aspek ekologi yang berkaitan dengan analisis kesesuaian lahan. Dengan kesesuaian lahan ini dapat dijadikan sebagai landasan apakah suatau wilayah layak atau tiak untuk dijadikan sebagai kawasan ekowisata. Penelitian ini bertujuan untuk menghitung indeks kesesuaian kawasan untuk pengembangan ekowisata mangrove. Metode yang digunakan adalah metode survey yaitu melakukan pengamatan langsung terhadap kondisi biofisik mangrove. Berdasarkan hasil penelitian potensi biofisik ekowisata mangrove yang ada di Kuri Caddi pada stasiun I termasuk dalam kategori S2 yaitu sesuai dengan presentase $77 \%$, stasiun II dan III termasuk dalam kategori S1 yaitu sangat sesuai dengan presentase $86 \%$. Dengan demikian disimpulkan bahwa potensi biofisik dari ekosistem mangrove sudah layak dan mendukung untuk dilakukan kegiatan ekowisata mangrove di Dusun Kuri Caddi Kabupaten Maros.
\end{abstract}

Kata kunci: Kesesuaian lahan, Ekowisata, Mangrove, Kuri caddi.

\begin{abstract}
In the development of mangrove ecotourism areas requires a study related to ecological aspects related to land suitability analysis. With this land suitability, it can be used as a basis for whether an area is feasible or not to be used as an ecotourism area. This study aims to calculate the area suitability index for the development of mangrove ecotourism. The method used is a survey method, namely direct observation of the biophysical condition of mangroves. Based on the results of the research on the biophysical potential of mangrove ecotourism in Kuri Caddi at station I, it is included in the S2 category, which is in accordance with the percentage of 77\%, stations II and III are included in the S1 category, which is very in accordance with the percentage of $86 \%$. Thus, it is concluded that the biophysical potential of the mangrove ecosystem is feasible and supports mangrove ecotourism activities in Kuri Caddi Hamlet, Maros Regency.
\end{abstract}

Keywords: Land suitability, Ecotourism, Mangroves, Kuri caddi

\section{PENDAHULUAN}

Salah satu sumber daya alam yang dapat diperbaharui adalah ekosistem mangrove dengan berbagai biota yang memiliki nilai ekonomis yang tinggi. Hutan mangrove adalah vegetasi hutan yang tumbuh dan berkembang dengan baik 
disepanjang pantai, muara sungai yang dipengaruhi oleh pasang surut air laut (Rajab, 2020).

Dalam pengembangan hutan mangrove sangat diperlukan untuk meningkatkan pendapatan ekonomi maupun kondisi sosial masyarakat sekitar, namun diperlukan pertimbangan, penilaian, dan analisis lingkungan (biofisik) yang baik bagi masyarakat tanpa harus memberikan dampak buruk bagi lingkungan dalam hal ini merusak ekosistem yang telah ada di dalam hutan mangrove (Kalitouw, 2015).

Salah satu wilayah di Sulawesi Selatan yang memiliki potensi ekosistem mangrove adalah Dusun Kuri Caddi, Desa Nisombalia, Kabupaten Maros. Secara ekologi, mangrove memiliki manfaat sebagai penyangga sedimentasi, tempat hidup biota laut, sumber kehidupan bagi manusia dan abrasi, serta pencegah intrusi air laut. Hutan mangrove dan ekosistem laut yang tidak dijaga kelestariannya akan mengalami kerusakan yang sangat berdampak negatif pada ekologi, ekonomi, dan sosial masyarakat (Usman, 2020).

Dusun Kuri Caddi, Desa Nisombalia Kabupaten Maros sangat potensial untuk dikembangkan menjadi kawasan ekowisata mangrove. Ekowisata merupakan salah satu alternatif pembangunan yang dapat membantu mengatasi masalah pemanfaatan yang sifatnya merusak dan mengancam kelestarian sumber daya (Rajab, 2014). Ekowisata adalah suatu bentuk perjalanan yang bertanggung jawab ke daerah alami yang lingkungannya dilindungi dan mampu meningkatkan kesejahteraan penduduk lokal. Bentuk perjalanan yang bertanggung jawab dapat dimaknai sebagai kegiatan wisata yang tidak memberikan merusak lingkungan, sehingga aktivitas dalam ekowisata seminimal mungkin tidak mengeksploitasi sumber daya (Rini, 2018).

Dalam mengelola suatu kawasan pesisir dan laut dengan konsep ekowisata memerlukan pemahaman ekologi terkait kesesuaian lahan dan daya dukung. ekowisata merupakan bentuk wisata yang tidak melampaui daya dukung suatu kawasan. Perhitungan daya dukung kawasan dimaksudkan untuk membatasi pemanfaatan yang berlebihan dan mencegah kerusakan ekosistem mangrove (Nugraha,. et all. 2013). 
Untuk menghitung daya dukung ekologis dengan menghitung jumlah wisatawan yang dapat melakukan kegiatan dalam kunjungan wisata tanpa menyebabkan kerusakan bagi lingkungan alam, di mana obyek tetap lestari pada tingkat manajemen (Wahdaniar, 2019). Oleh karena itu, perlu adanya penelitian mengenai kesesuaian lahan untuk dijadikan sebagai kawasan ekowisata mangrove.

Berdasarkan uraian latar belakang di atas maka dapat dirumuskan masalah yaitu bagaimana kesesuaian lahan wisata mangrove Kuri Caddi, Desa Nisombalia, Kabupaten Maros. Adapun tujuan penelitian ini adalah untuk menghitung indeks kesesuaian kawasan untuk pengembangan ekowisata mangrove

\section{METODE PENELITIAN}

Penelitian dilaksanakan pada bulan Juli - Agustus, pengambilan data lapangan di laksanakan di Dusun Kuri Caddi, Kecamatan Marusu, Kabupaten Maros Sulawesi Selatan. Jenis penelitian yang digunakan dalam penelitian ini yaitu penelitian kualitatif.

Alat dan bahan yang digunakan dalam penelitian ini meliputi peta penelitian, Global Positioning System (GPS), kamera digital, alat tulis, pH meter, salinometer, perahu, tali transek, botol sampel, alcohol 70\%, aquades, coolbox (untuk wadah biota) dan substrat mangrove serta buku identifikasi mangrove, moluska dan crustacea. Jenis data yang diambil dalam penelitian ini tersaji pada Tabel 1.

Tabel 1. Jenis dan Sumber Data dalam Penelitian

\begin{tabular}{llll}
\hline No & \multicolumn{1}{c}{ Parameter } & Jenis Data & \multicolumn{1}{c}{ Sumber Data } \\
\hline & Parameter Fisik & & \\
\hline 1 & Geografi & Sekunder & BPS Kabupaten Maros \\
2 & Demografi & Sekunder & BPS Kabupaten Maros \\
3 & Aksesibilitas & Sekunder & BPS Kabupaten Maros \\
4 & Kondisi Osanografi & Sekunder & BPS Kabupaten Maros \\
5 & Pasang Surut & Sekunder & BPS Kabupaten Maros \\
6 & Panjang/Luas & Primer & Kelompok Pengelola/Kantor \\
& Mangrove & & Desa \\
7 & Durasi Wisata & Primer & Kelompok Pengelola/Kantor \\
& & & Desa \\
\hline & Parameter Biologi & Primer & \\
\hline 1 & Lebar Mangrove & Primer & Survey Lapangan \\
\hline
\end{tabular}




\begin{tabular}{llll}
\hline 2 & Kerapatan Mangrove & Primer & Survey Lapangan \\
3 & Jenis Mangrove & Primer & Survey Lapangan \\
4 & Fauna Mangrove & Primer & Survey Lapangan \\
5 & Tipe Substrat & Primer & Survey Lapangan \\
\hline
\end{tabular}

Kesesuaian ekowisata ekosistem mangrove dalam kegiatan ekowista memerlukan analisis suatu kelayakan, untuk itu penelitian akan mempertimbangkan 4 parameter dengan 4 klasifikasi penilaian yaitu kategori S1 (sangat sesuai), kategori S2 (sesuai), S3 (cukup sesuai), dan kategori N (tidak sesuai) dapat dilihat pada Tabel 2 berikut:

Tabel 2. Parameter Kelas Kesesuaian

\begin{tabular}{|c|c|c|c|c|c|c|c|c|c|}
\hline \multirow{2}{*}{ Parameter } & \multirow{2}{*}{ Bobot } & \multicolumn{8}{|c|}{ Kelas Kesesuaian (Skor) } \\
\hline & & S1 & Skor & $\mathbf{S 2}$ & Skor & $\mathbf{S 3}$ & Skor & $\mathbf{N}$ & Skor \\
\hline $\begin{array}{l}\text { Ketebalan } \\
\text { mangrove } \\
(\mathrm{m})\end{array}$ & 5 & $>500$ & 3 & $\begin{array}{c}>200- \\
500\end{array}$ & 2 & $50-200$ & 1 & $<50$ & 0 \\
\hline $\begin{array}{l}\text { Kerapatan } \\
\text { mangrove } \\
\left(100 \mathrm{~m}^{2}\right)\end{array}$ & 3 & $>15-25$ & 3 & $>10-15$ & 2 & $5-10$ & 1 & $<5$ & 0 \\
\hline $\begin{array}{l}\text { Jenis } \\
\text { mangrove }\end{array}$ & 3 & $>5$ & 3 & $3-5$ & 2 & $1-2$ & 1 & 0 & 0 \\
\hline $\begin{array}{l}\text { Obyek } \\
\text { biota }\end{array}$ & 1 & $\begin{array}{l}\text { Ikan, } \\
\text { udang, } \\
\text { kepiting, } \\
\text { moluska } \\
\text { reptil, } \\
\text { burung }\end{array}$ & 3 & $\begin{array}{c}\text { Ikan, } \\
\text { udang, } \\
\text { kepiting, } \\
\text { moluska }\end{array}$ & 2 & $\begin{array}{c}\text { Ikan, } \\
\text { moluska }\end{array}$ & 1 & $\begin{array}{c}\text { Salah } \\
\text { satu } \\
\text { biota } \\
\text { air }\end{array}$ & 0 \\
\hline
\end{tabular}

Sumber: Yulianda (2007) dalam (Rini, Setyobudiandi, \& Kamal)

Keterangan:

Nilai maksimum $=36$

S1 = Sangat sesuai, dengan nilai $80-100 \%$

S2 = Sesuai, dengan nilai $60-<80 \%$

S3 = Sesuai bersyarat, dengan nilai $35-<60 \%$

$\mathrm{N} \quad=$ Tidak sesuai, dengan nilai $<35 \%$

Formula yang digunakan untuk menentukan kesesuaian ekowisata mangrove adalah sebagai berikut :

$\mathrm{IKW}=\sum \frac{N i}{N m a k s} \times 100 \%$

Keterangan:

IKW = Indeks kesesuaian wisata mangrove

$\mathrm{N}_{\mathrm{i}} \quad=$ Nilai parameter ke-i (Bobot $\mathrm{x}$ skor) 
P-ISSN 2580 - 7781

E-ISSN $2615-3238$

$\mathrm{N}_{\text {maks }}=$ Nilai maksimal

\section{HASIL PENELITIAN DAN PEMBAHASAN}

Secara administrasi Dusun Kuri Cadi terletak di Desa Nosambalia, Kecamatan Marusu, Kabupaten Maros. Desa Nosambalia berstatus desa definitif dan tergolong pulau sebagai desa swasembada. Desa Nosambalia termasuk dalam tipe desa pesisir pantai yang memiliki luas wilayah $25,43 \mathrm{~km}^{2}$, dengan empat dusun di dalamnya yaitu, Dusun Mambue, Tala-Tala, Kuri Lompo dan Kuri Caddi. Batas administratif yaitu:

1. Sebelah Utara berbatasan dengan Kecamatan Maros Baru;

2. Sebelah Selatan berbatasan dengan Kota Makassar;

3. Sebelah Timur berbatasan dengan Turikale dan Mandai;

4. Sebelah Barat berbatasan dengan Selatan Makassar.

Penelitian dilaksanakan di Dusun Kuri Caddi dimana untuk menuju ke sana memiliki dua jalur yaitu jalur darat, masuk lorong di Kuri Lompo untuk menuju Kuri Caddi dengan kondisi jalan berbatu, bergelombang, becek, berlumpur, dan bahkan harus melewati beberapa jembatan kayu yang kurang baik. Jalur kedua yaitu jalur laut, menggunakan jalur ini harus memesan kapal/ perahu nelayan yang banyak berlabuh di Kuri Lompo. Tapi kebayakan orang jika ingin berwisata ke Kuri Caddi menggunakan jalur darat. 
Dalam melakukan analisis kesesuaian lahan untuk ekowisata mangrove dalam penelitian ini ditentukan 3 stasiun penelitian.

Tabel 3. Parameter Kesesuaian Ekowisata Mangrove Stasiun I

\begin{tabular}{clcccc}
\hline \multicolumn{6}{c}{ Parameter Kelas Kesesuaian Stasiun I } \\
\hline No. & \multicolumn{1}{c}{ Parameter } & Bobot & Hasil & Skor & $\begin{array}{c}\text { Bobot X } \\
\text { Hasil }\end{array}$ \\
\hline 1 & $\begin{array}{l}\text { Ketebalan Mangrove } \\
(\mathrm{m})\end{array}$ & 5 & 269 & 2 & 10 \\
\hline 2 & $\begin{array}{l}\text { Kerapatan Mangrove } \\
\text { (pohon/ha) }\end{array}$ & 3 & 1500 & 2 & 6 \\
\hline 3 & Jenis mangrove & 3 & 13 Jenis & 3 & 9 \\
\hline 4 & Obyek Biota & 1 & $\begin{array}{c}\text { Ikan, udang, kepiting, } \\
\text { molusaka, reptil, dan } \\
\text { burung }\end{array}$ & 3 & 3 \\
\hline & & Jumlah & & 28 \\
\hline & IKW \\
& $=\sum\left(\frac{N i}{N \text { Max }}\right) \times 100 \%$ & $77 \%$
\end{tabular}

Sumber: Data Primer, 2021

Pada Tabel 3 di atas dapat dilihat dari hasil presentase kesesuaian lahan untuk ekowisata mangrove yang terdapat pada stasiun I termasuk dalam kategori S2 yaitu kategori sesuai dengan presentase $77 \%$.

Pada stasiun II, diketahui parameter kesesuaian lahan untuk ekowisata sebagai berikut:

Tabel 4. Parameter Kesesuaian Ekowisata Mangrove Stasiun II

\begin{tabular}{clcccc}
\hline \multicolumn{5}{c}{ Parameter Kelas Kesesuaian Stasiun II } \\
\hline No. & \multicolumn{1}{c}{ Parameter } & Bobot & Hasil & Skor & $\begin{array}{c}\text { Bobot X } \\
\text { Hasil }\end{array}$ \\
\hline 1 & $\begin{array}{l}\text { Ketebalan Mangrove } \\
(\mathrm{m})\end{array}$ & 5 & 269 & 2 & 10 \\
\hline 2 & $\begin{array}{l}\text { Kerapatan Mangrove } \\
\text { (pohon/ha) }\end{array}$ & 3 & 2500 & 3 & 9 \\
\hline 3 & Jenis mangrove & 3 & 13 Jenis & 3 & 9 \\
\hline 4 & Obyek Biota & 1 & $\begin{array}{c}\text { Ikan, udang, } \\
\text { kepiting, molusaka, } \\
\text { reptil, dan burung }\end{array}$ & 3 & 3 \\
\hline & Jumlah & NKW $=\sum\left(\frac{N i}{N \text { Max }}\right) \times 100 \%$ & $86 \%$ \\
\hline
\end{tabular}

Sumber: Data Primer, 2021 
P-ISSN 2580 - 7781

E-ISSN $2615-3238$

Pada Tabel 4 di atas hasil persentase kesesuaian lahan untik ekowisata mangrove pada stasiun II termasuk dalam kategori S1 yaitu sangat sesuai dengan presentase $86 \%$.

Pada stasiun III, diketahui parameter kesesuaian lahan untuk ekowisata sebagai berikut:

Tabel 5. Parameter Kesesuaian Ekowisata Mangrove Stasiun III

\begin{tabular}{clcccc}
\hline \multicolumn{6}{c}{ Parameter Kelas Kesesuaian Stasiun III } \\
\hline No. & \multicolumn{1}{c}{ Parameter } & Bobot & Hasil & Skor & $\begin{array}{c}\text { Bobot X } \\
\text { Hasil }\end{array}$ \\
\hline 1 & $\begin{array}{l}\text { Ketebalan Mangrove } \\
(\mathrm{m})\end{array}$ & 5 & 269 & 2 & 10 \\
\hline 2 & $\begin{array}{l}\text { Kerapatan Mangrove } \\
\text { (pohon/ha) }\end{array}$ & 3 & 1800 & 3 & 9 \\
\hline 3 & Jenis mangrove & 3 & 13 Jenis & 3 & 9 \\
\hline 4 & Obyek Biota & 1 & $\begin{array}{c}\text { Ikan, udang, } \\
\text { kepiting, molusaka, } \\
\text { reptil, dan burung }\end{array}$ & 3 & 3 \\
\hline & Jumlah & & 31 \\
\hline & $I K W=\sum\left(\frac{N i}{N \text { Max }}\right) \times 100 \%$ & $86 \%$
\end{tabular}

Sumber: Data Primer, 2021

Dari hasil Tabel 5 di atas presentase kesesuaian lahan untuk ekowisata mangrove yang terdapat pada stasiun III termasuk dalam kategori S1 sangat sesuai dengan presentase $86 \%$.

\section{KESIMPULAN}

Tingkat kesesuaian lahan untuk ekowisata mangrove Kuri Caddi Desa Nisombalia Kabupaten Maros sudah sesuai dari empat indikator yaitu ketebalan, kerapatan, jenis mangrove, dan obyek biota, yang dimana keadaan biologis dari hutan mangrove sudah mendukung untuk dilakukan kegiatan ekowisata.

\section{DAFTAR PUSTAKA}

Kalitouw, D. W. 2015. Potensi Ekonomi Ekosistem Hutan Mangrove Di Desa Kulu, Kecamatan Wori Kabupaten Minahasa Utara. Jurnal Risalah Kebijakan Pertanian dan Lingkungan. Institut Pertanian Bogor (IPB). Bogor. 
Nugraha, H.P., Indarjo., Helmi M. 2013. Studi kesesuaian dana daya dukung kawasan untuk rekreasi pantai di Pantai Panjang Kota Bengkulu. Journal of Marine Research, 2(2), 130-139.

Rajab, M.A. 2020. Potensi Biofisik Ekosistem Mangrove untuk Ekowisata di Kampung Parambu, Kabupaten Jeneponto. Jurnal Kepariwisataan dan Hospitalitas, 4(1), 25-29.

Rajab, M.A. 2014. Pengelolaan Pulau Kecil Untuk Ekowisata Bahari (Studi Kasus Pulau Liukang Loe, Kabupaten Bulukumba). Institut Pertanian Bogor (IPB). Bogor.

Rini., et all. 2018. Kajian Kesesuaian, Daya Dukung dan Aktivitas Ekowisata di Kawasan Mangrove Lantebung Kota Makassar. Jurnal Pariwisata, 5(1). Universitas Bina Sarana Informatika. Jakarta.

Usman, A.H.A., et all. 2020. The Miracle of Mangrove, Peningkatan Pengetahuan dan Kesadaran Masyarakat Kuri Caddi terhadap Keberadaan Mangrove. Agrokreatif : Jurnal Pengabdian Kepada Masyarakat, 6(1): 24-28

Wahdaniar. 2019. Daya Dukung dan Kesesuaian Lahan Ekowisata Mangrove Tongke-Tongke Kabupaten Sinjai Sulawesi Selatan. Jurnal Ilmu Lingkungan, 17(3). Universitas Diponegoro. Semarang. 